TP Periodica Polytechnica

Mechanical Engineering

60(3), pp. 142-151, 2016

DOI: $10.3311 /$ PPme. 8633

Creative Commons Attribution (i)

RESEARCH ARTICLE

\section{Characterization of the Mechanical Behaviour of Carbon Fiber Composite Laminate under Low Velocity Impact}

\author{
Djilali Beida Maamar ${ }^{1}$, Zenasni Ramdane ${ }^{1^{*}}$
}

Received 04 October 2015; accepted after revision 18 March 2016

\begin{abstract}
The main purpose of the present investigation was to determine the damages generated by the low velocities with the help of the experimental method (Impact by a drop test) and the finite element method. The commercial transient finite element package LS-dyna used to model the effect of slug impactor and circular notch induced damage in composite material subjected to low velocity impact. The studied composite material was T800S/M21 made of carbon/epoxy. The effect of circular notch was examined. The composite material was subjected to stainless steel slug impactor in the transverse direction dropping the composite laminate at the center with three different velocities $(2.85 \mathrm{~m} / \mathrm{s}, 3.47 \mathrm{~m} / \mathrm{s}$ and $4.17 \mathrm{~m} / \mathrm{s})$. The analysis was carried out using the model MAT59 for laminate and a rigid body model MAT20 for the slug impactor. The automatic_surface to_surface has been used to model the contact between the impactor and the laminate and the contact_automatic_surface_to_surface_tiebreak to simulate delamination between layers. A good agreement had been shown between the finite element results and the experimental values obtained from the drop tower test. The impact load, impact energy, displacements and the maximal were reported as function of the impact time. The delamination area and the layer impact energy were represented as function of layer orientations. By increasing the impact velocity, the displacement, the delamination area, the contact load and the impact energy increases respectively. The circular notch had an effect on the displacement values; this values increases in respect of the impact velocities. At the reverse, the contact load decreases respectively in function of the velocities.
\end{abstract}

\section{Keywords}

low velocity, composite material, finite element, slug impactor, circular notch, stacking sequence, Mat59, Mat20, delamination area

\footnotetext{
${ }^{1}$ Department of Mechanics University of Mostaganem, Algeria

*Corresponding author, e-mail: r_zenasni@hotmail.com
}

\section{Introduction}

The fibrous composites are being increasingly used in load bearing structures due to number of advantages over conventional materials: high specific strength and stiffness, good fatigue performance and corrosion resistance. A serious obstacle to more widespread use is their sensitivity to impact and static loads in the thickness direction. As composites have demonstrated to be very venerable to out of plane impact, which cause barely visible impact damage (BVID) reportedly contributes up to $60 \%$ loss in structures' compressive strength and major reason of catastrophic failures. The energy absorbed during impact is mainly dissipated by a combination of matrix damage, fibre fracture and fibre-matrix de-bonding, which leads to significant reductions in the resistance. In ballistic impacts the damage is localized and clearly visible by external inspection, while low velocity impact involves long contact time between impactor and target, which produces global structure deformation with undetected internal damage at points far from the contact region. Low velocity impact is often simulated by simple static indentation-flexure tests, neglecting the influence of dynamic effects. It is also suggested the complete model to take into account the full dynamic behavior of the laminates. Abrate et al. [1] have investigated the delamination of two laminated composite graphite/PEEK and graphite/BMI under low velocity impact. The range number of layers varies from 9 to 95 plies. The obtained result shown a higher delamination threshold load and higher damage resistance. The resulting damage is not normally visible on the specimen surface nor is easily detected and grows rapidly during normal service. The area has been under active research for a quite some time. Some of the relevant articles addressing this issue found in the literature are presented below. The strategy of reducing the stiffness of damaged plies to a certain fraction without considering the degree of damage was used by some investigators $[2,3]$. Other researchers applied damage theory of continuum mechanics to address the internal damage. They initiated the stress-strain relation for the actual damaged by introducing a fourth-order damage operator to transform the compliance matrix according to the damage states. Based on this work, several investigations 
were conducted in the subjects such as tension of composite laminates with holes and high velocity impact of composite laminates [4-7]. They adopted the simple assumption that when damage occurs, the mechanical properties would reduce to certain levels. The impact induced delamination another important damage mode was combined because the level of impact energy to initiate de-lamination is low and the post-impact compressive strength reduces dramatically. New techniques used in [8] to model the laminate as a stack of elements tied by contact interface conditions, allows the inter-laminar layers to model and predict strength reduction. Because of the complex nature, a simple and effective criterion for the BVID prediction and damage/delamination initiation is still lacking. The stability of simulation was another important issue to be considered, when changes of material properties were taken into account. Cantwell and Morton proposed a pine tree damage pattern and a reversed pine tree damage pattern for the impact-induced matrix cracks in thick and thin thickness laminated composites,

Respectively [9], Freitas proposed a pine tree damage pattern with vertical matrix cracks on the bottom layer [10]. Since 1980s, many researchers have analytically and experimentally investigated the low velocity impact behaviour of composite laminated structures. Most composite structures will be under some level of stress when impacted. For example, the upper skin of the main wing of the aircraft will be mainly under inplane compressive load during flight and the lower one will be under in-plane tensile load. So, foreign objects like hail and debris in the runway shall give an impact to 638. Umar Farooq and Karl Gregory [11] have studied a composite laminated structure under in-plane load. However, a few studies on the impact behaviour of the composite laminates under inplane load have been published. In 1985, Chen and Sun [13] have developed a finite element program to analyze the impact response of the composite laminate under biaxial in-plane load. Using the finite element program they solved for three cases of in-plane load, tension/tension load of 3 times of critical buckling load of the plate, compression/compression load of $75 \%$ of it, and no initial in-plane load. The impact condition is the case that the mass of the impactor is very small and the impact velocity is very high. They concluded that the initial tensile in-plane load tends to intensify the contact force while reducing the contact time, and an opposite conclusion is obtained for an initial compressive in-plane load. After their study, it is very rare to find another analytical result on the impact behaviour of the composite laminates under in-plane load. Introduction $\mathrm{Wu}$ and Chang [14] have conducted a transient dynamic finite element analysis for studying the response of laminated composite plates subjected to transverse impact loading by a foreign object. They have calculated displacements, the transient stress and the strain distributions through the thickness of laminate during the impact event. Gaurav Nilakantan et al. [15] have used the multiscale modelling techniques to analyze the impact damage of woven fabric by the finite element. On the other hand, Manish Khandelwal et al. [16] have studied the delamination initiation in FRP under low velocity impact. The analysis was conducted using 3D finite element. The composite material studied were Graphite/epoxy and hybrid Glass-Graphite Epoxy. F. Mili, B. Necib [17], investigated the effect of stacking sequence on the damage induced in E-glass/epoxy composite to determine the damage mechanisms of unidirectional laminated composites under localized impacts. The projectile velocities at low range $(0.54-3.10 \mathrm{~m} / \mathrm{s})$. They used circular plates are symmetrical laminates which are composed of ten plies and have three different cross-ply stacking sequences: $\left[0 / 90_{6} / 0_{2}\right],\left[0_{3} / 90_{4} / 0_{3}\right]$ and $\left[0_{4} / 90_{2} / 0_{4}\right]$. The identification of the matrix cracks and the delamination at the interfaces has allowed determining the initiation and extension criteria of the damage. Baozhong Sun et al. [18], studied the low-velocity impact characters of 3-D braided carbon/epoxy composites were investigated from experimental and finite element simulation approaches. The quasi-static tests were carried out at a constant velocity of $2 \mathrm{~mm} / \mathrm{min}$. The low-velocity tests were conducted at the velocities from $1 \mathrm{~m} / \mathrm{s}$ to $6 \mathrm{~m} / \mathrm{s}$ (corresponding to the impact energy from $3.22 \mathrm{~J}$ to $116 \mathrm{~J}$ ) on Instron Dynatup machine. Based on the model, a user-defined material subroutine (VUMAT) has been compiled by FORTRAN and connected with commercial finite element code ABAQUS/ Explicit to calculate the impact damage. A. Riccio et al. [19], investigate the delamination and damage mechanisms, such as matrix cracks, fibre-matrix debonding and fibre failure can appear as a consequence of impact events with foreign objects under in service conditions and maintenance operations. They used a numerical procedure, able to take into account the failure modes interaction in composite laminated.

\section{Laminate and impactor \\ 2.1 Composite laminate}

The studied composite material was T800S/M21 of epoxy matrix reinforced by carbon fibers of stacking sequence $[-45,45,0,90,0,0,-45,45,0]_{s}$, see Fig. 1 . The fiber volume fraction was about of $33 \%$. They were manufactured rectangular laminate panels using moulding conditions included a temperature of $315^{\circ} \mathrm{C}$ and a pressure of 2 Bar for $15 \mathrm{~min}$ followed by the same temperature with 20 Bar for $20 \mathrm{~min}$, and finally $10 \mathrm{~min}$ for $20 \mathrm{Bar}$ at $140{ }^{\circ} \mathrm{C}$. The dimensions of the specimens were $125 \times 75 \times 4.5 \mathrm{~mm}^{3}$, with a ply thickness was about $0.25 \mathrm{~mm}$. In Table 1, we present the mechanical properties of the composite laminate. The notch had a great effect on the impacted laminate; circular notch of diameter $5 \mathrm{~mm}$ was drilled in all specimens at the location shown in Fig. 2. 


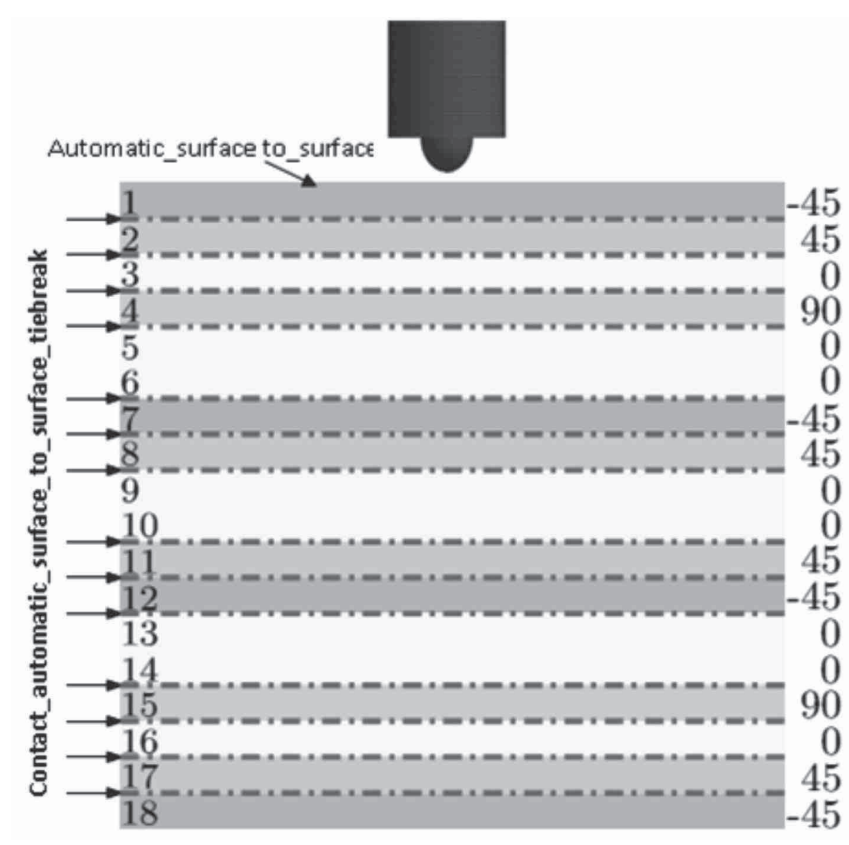

Fig. 1 Stacking sequences

Table 1 Mechanical properties of the composite material and the impactor [21]

\begin{tabular}{llllll}
\hline $\mathrm{E}_{11}$ & $\mathrm{E}_{22}$ & $\mathrm{E} 33$ & & & $v_{13}$ \\
$\mathrm{GPa}$ & $\mathrm{GPa}$ & $\mathrm{GPa}$ & $v_{12}$ & $v_{23}$ & 0.35 \\
\hline 165 & 7.64 & 7.64 & 0.35 & 0.4 & 0.35 \\
\hline $\mathrm{Xt}$ & $\mathrm{Xc}$ & $\mathrm{Yt}$ & $\mathrm{Yc}$ & $\mathrm{Zt}$ & $\mathrm{Zc}$ \\
$\mathrm{GPa}$ & $\mathrm{GPa}$ & $\mathrm{GPa}$ & $\mathrm{GPa}$ & $\mathrm{GPa}$ & $\mathrm{GPa}$ \\
\hline 2.2 & 1.2 & 0.045 & 0.28 & 0.045 & 0.7 \\
\hline $\mathrm{G}_{12}$ & $\mathrm{G}_{23}$ & $\mathrm{G}_{13}$ & $\mathrm{~S}_{12}$ & $\mathrm{~S}_{23}$ & $\mathrm{~S}_{13}$ \\
$\mathrm{GPa}$ & $\mathrm{GPa}$ & $\mathrm{GPa}$ & $\mathrm{GPa}$ & $\mathrm{GPa}$ & $\mathrm{GPa}$ \\
\hline 5.61 & 2.75 & 5.61 & 0.05 & 0.05 & 0.05 \\
\hline $\mathrm{E} \mathrm{impactor}$ & $\rho$ impactor & & & & \\
$\mathrm{GPa}$ & $\mathrm{Kg} / \mathrm{m}^{3}$ & & & & \\
\hline 207 & 7850 & 0.3 & & &
\end{tabular}

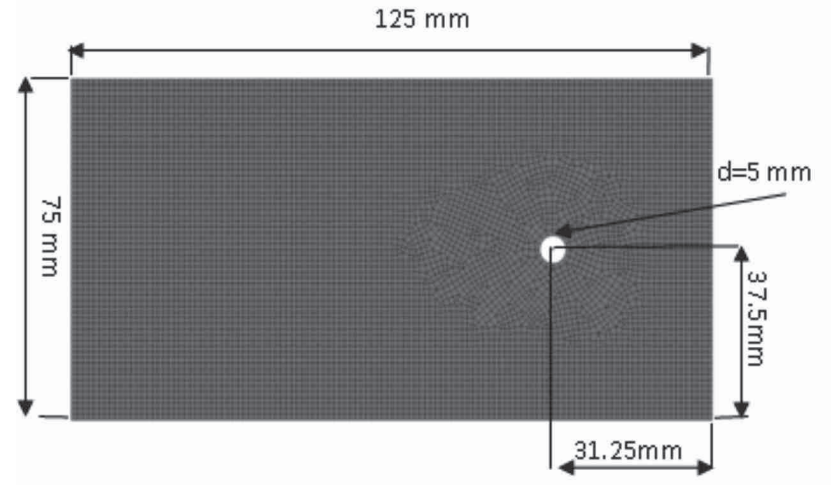

Fig. 2 Location of circular notch drilled in laminate plate

\subsection{Impactor and impact test}

During the numerical simulation, slug impactor of masse of about 2368 g was used; in Fig. 3; we present the impactor shape and the geometrical properties. The material of the impactor was made of stainless steel, see Table 1 . The experiments are performed in three impact velocities $(2.85 \mathrm{~m} / \mathrm{s}, 3.47 \mathrm{~m} / \mathrm{s}$ and $4.17 \mathrm{~m} / \mathrm{s}$ ). The slug impactor targeted the plate by the hemispherical front head. Specimens were tested according to ASTM D7136/ D7136M-05 [20] at temperature of $20^{\circ} \mathrm{C}$ and a pressure about 1 bar in order to determinate the maximum load and the energy required to impact delamination. The impact test was conducted in drop tower with load cell of $45 \mathrm{KN}$ capacity was used, and instantaneous force data were recorded during impact at $163 \mathrm{kHz}$. All sides of the laminate were clamped; the slug impactor had a free boundary about the $\mathrm{z}$ axis.

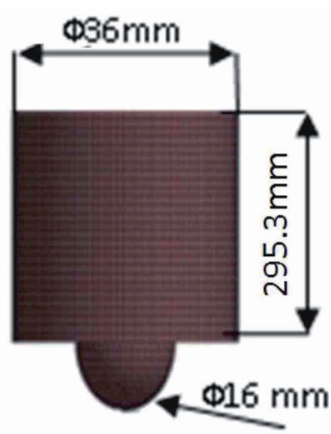

Fig. 3 Slug impactor shape with geometrical properties

\subsection{Numerical modeling}

The impact problem can be described as shown in Fig. 4. An impactor of a mass $m$ and shape drops on the centre of the laminated plate with a velocity $\mathrm{V}$.

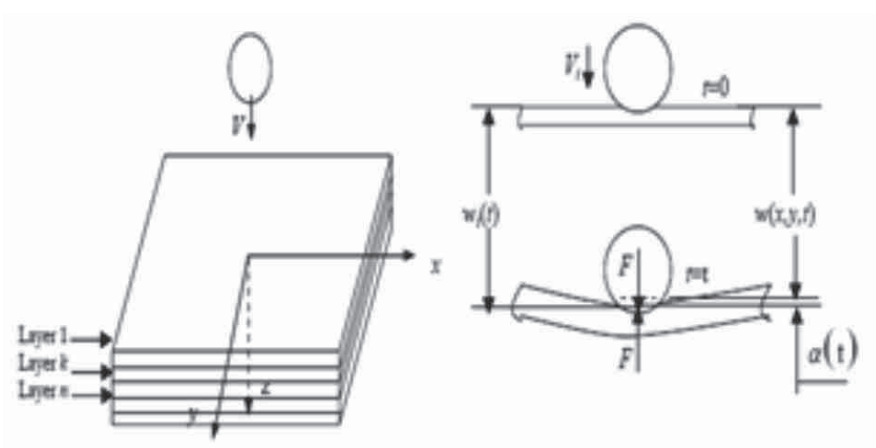

Fig. 4 A basic model for the impact damage [1]

Many factors such lay- up configuration, impactor size and shape, mechanical properties of composite, environment, presence of notch and cracks, impact velocity can affect the impact behavior and damage pattern. 
The impact tests were simulated using the commercial finite element code LS-DYNA Version 971, and were run in double precision mode. Since one of the scopes of the analysis was the prediction of damage development, a 3D model of the ply was selected, to obtain a more accurate description of the stress distribution along the ply thickness. Each ply was modelled through a single layer of three-dimensional eight nodes finite elements. Among the lamina constitutive models available in LS-DYNA, the Mat Composite Failure Option Model (MAT059, Option = Solid) [22], able to model the progressive damage of the material on the basis of a three-dimensional stress based failure criterion, was chosen in this work. Although the selection of MAT59 in shell formulation has been discussed in several applications available in literature [23], works or detailed descriptions investigating its behaviour in 3D formulations are scarce and only few information. Solid elements are able to capture fully threedimensional states of stress and are generally used to model thick parts or continua. In contrast, parts that are relatively thin in one direction are generally modeled with shell elements. To model a thin part with solids can be expensive since the smallest dimension of a solid will control its time step, and generally two or more solid elements through the thickness are required to produce an accurate response. For solid elements, the corresponding element formulations exist with more options if shear locking is for example present. If eight-noded brick elements are to be used, the recommended element formulations are either the default formulation with one integration point, denoted as "ELFORM=1" or the fully integrated solid formulation, denoted as "ELFORM=2" which provides eight integration points on the element surface. The biggest disadvantage to one-point integration is the need to control the zero energy modes, which arise, called hourglassing modes. Undesirable hourglass modes tend to have periods that are typically much shorter than the periods of the structural response, and they are often observed to be oscillatory. However, hourglass modes that have periods that are comparable to the structural response periods may be a stable kinematic component of the global deformation modes and must be admissible. One way of resisting undesirable hourglassing is with a viscous damping or small elastic stiffness capable of stopping the formation of the anomalous modes but having a negligible effect on the stable global modes. Ply element deleting criterion was added by using ADDEROSION card, which allows elements to be deleted from the calculation. The in plane stresses were calculated by the Eq. (1), while the coefficient of stiffness's in out of plane, of the laminated plate where calculated using the Eq. (2).

$$
\left\{\begin{array}{l}
\sigma_{x} \\
\sigma_{y} \\
\tau_{x y}
\end{array}\right\}=\left[\begin{array}{lll}
\bar{Q}_{11} & \bar{Q}_{12} & \bar{Q}_{16} \\
\bar{Q}_{12} & \bar{Q}_{22} & \bar{Q}_{26} \\
\bar{Q}_{16} & \bar{Q}_{26} & \bar{Q}_{66}
\end{array}\right]\left\{\begin{array}{c}
\varepsilon_{x} \\
\varepsilon_{y} \\
\gamma_{x y}
\end{array}\right\}
$$

The transformed transformed reduced stiffness coefficients are calculated by Eq. (2).

$$
\begin{aligned}
& \bar{Q}_{11}=Q_{11} m^{4}+2\left(Q_{12}+2 Q_{66}\right) m^{2} n^{2}+Q_{22} n^{4} \\
& \bar{Q}_{12}=\left(Q_{11}+Q_{22}-4 Q_{66}\right) m^{2} n^{2}+Q_{12}\left(m^{4}+n^{4}\right) \\
& \bar{Q}_{22}=Q_{11} n^{4}+2\left(Q_{12}+2 Q_{66}\right) m^{2} n^{2}+Q_{22} m^{4} \\
& \bar{Q}_{66}=\left(Q_{11}+Q_{22}-2 Q_{12}\right) m^{2} n^{2}+Q_{66}\left(m^{2}-n^{2}\right)^{2} \\
& \bar{Q}_{16}=Q_{22} m n^{3}+Q_{11} m^{3} n-\left(Q_{12}+2 Q_{66}\right) m n\left(m^{2}-n^{2}\right) \\
& \bar{Q}_{26}=-Q_{22} m^{3} n+Q_{11} m n^{3}+\left(Q_{12}+2 Q_{66}\right) m n\left(m^{2}-n^{2}\right)
\end{aligned}
$$

The on axis stiffness coefficients are:

$$
\begin{gathered}
Q_{11}=\frac{E_{1}}{1-\gamma_{12} \gamma_{21}} \\
Q_{22}=\frac{E_{2}}{1-\gamma_{12} \gamma_{21}} \\
Q_{12}=\frac{\gamma_{12} E_{2}}{1-\gamma_{12} \gamma_{21}} \\
Q_{66}=G_{66}
\end{gathered}
$$

The transformed reduced coefficients are:

$$
\bar{Q}_{i j}=\bar{C}_{i j}-\frac{\bar{C}_{i 3} \bar{C}_{3 j}}{\bar{C}_{33}}, \quad i, j=1,2,6
$$

Where:

$m=\cos (\theta), n=\sin (\theta)$

$\theta$ : Angle ply orientation

$E_{1}$ : Elastic modulus in direction 1

$E_{2}$ : Elastic modulus in direction 2

$G_{12}:$ Shear modulus in plane $1-2$

$t_{k}$ : Ply thickness

The in plane loading and the curvatures moments are calculated using Eq. (3).

$$
\left\{\begin{array}{l}
\{N\} \\
\{M\}
\end{array}\right\}=\left[\begin{array}{ll}
{[A]} & {[B]} \\
{[B]} & {[D]}
\end{array}\right]\left\{\begin{array}{l}
\{\varepsilon\} \\
\{K\}
\end{array}\right\}
$$

The matrices A, B and D were calculated by Eq. (4)

$$
\begin{aligned}
A_{i j} & =\sum_{k=1}^{n}\left[\bar{Q}_{k}\right] t_{k} \\
D_{i j} & =\sum_{k=1}^{n}\left[\bar{Q}_{k}\right]\left(t_{k} \bar{Z}_{k}^{2}+\frac{t_{k}^{3}}{12}\right) \\
B_{i j} & =\sum_{k=1}^{n}\left[\bar{Q}_{k}\right] t_{k} \bar{Z}_{k}
\end{aligned}
$$


The composite failure model Mat-59 called elastic plastic material model

\section{Failure criteria}

Thru-Thickness shear failures

- Longitudinal $\left(\sigma_{11}>0\right)$

$$
\left(\frac{\sigma_{11}}{X}\right)^{2}+\left(\frac{\sigma_{13}}{S_{1}}\right)^{2} \geq 1
$$

Transverse $\left(\sigma_{22}>0\right)$

$$
\left(\frac{\sigma_{22}}{Y}\right)^{2}+\left(\frac{\sigma_{23}}{S_{2}}\right)^{2} \geq 1
$$

- Delamination failures

$$
\left(\frac{\sigma_{23}}{Z}\right)^{2}+\left(\frac{\sigma_{13}}{S_{1}}\right)^{2}+\left(\frac{\sigma_{23}}{S_{2}}\right)^{2} \geq 1
$$

- Compressive failures

a. Longitudinal compressive failure (if the following is met:

$$
\left(\frac{\sigma_{11}}{X_{c}}\right)^{2} \geq 1
$$

Transverse compressive failure occurs if the following is met

$$
\left(\frac{\sigma_{22}}{S_{12}+S_{23}}\right)^{2}+\left(\left(\frac{Y_{c}}{S_{12}+S_{23}}\right)^{2}-1\right) \frac{\sigma_{22}}{I Y_{c}}+\left(\frac{\sigma_{12}}{S_{12}}\right)^{2}+\left(\frac{\sigma_{13}}{S_{23}}\right)^{2} \geq 1
$$

Thru-thickness compressive failure occurs if the following is met:

$$
\left(\frac{\sigma_{33}}{S_{13}+S_{23}}\right)^{2}+\left(\left(\frac{Z_{c}}{S_{13}+S_{23}}\right)^{2}-1\right) \frac{\sigma_{33}}{I Z_{c}}+\left(\frac{\sigma_{13}}{S_{13}}\right)^{2}+\left(\frac{\sigma_{23}}{S_{13}}\right)^{2} \geq 1
$$

\section{Numerical results and discussion}

The impactor was modeled as a hemispherical rigid body with rigid LS-DYNA material model (MAT-RIGID). Its initial velocity and mass were set depending on the energy level considered. Contact between the impactor and the whole laminate was simulated using the AUTOMATIC-SURFACE-TO-SURFACE penalty based contact algorithm (Fig. 5), with the interface parameters listed below:

ERATEN $=7.65 \mathrm{e}-4 \mathrm{KN} / \mathrm{mm}^{3}$ : Normal energy release rate used in damage calculation

ERATES $=0.00125 \mathrm{KN} / \mathrm{mm}^{3}$ : Shear energy release rate used in damage calculation

NFLS $=0.06 \mathrm{GPa}$ Normal failure stress

SFLS $=0.06 \mathrm{GPa}$ Shear failure stress

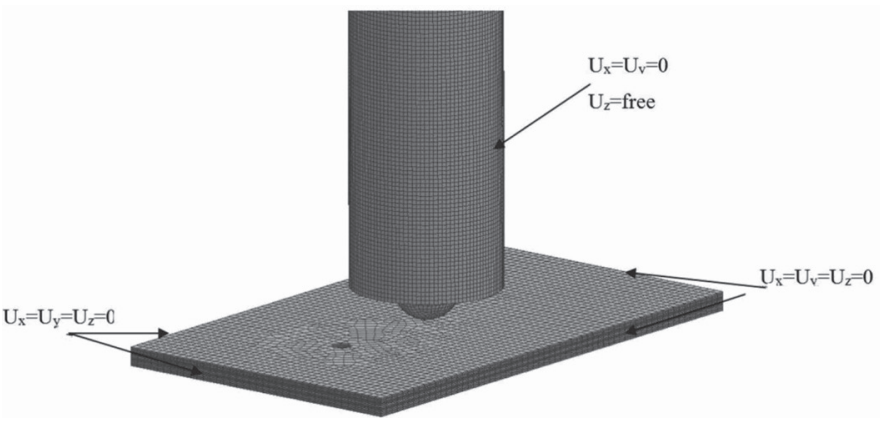

Fig. 5 Mesh scheme of the composite under drop weight impact

In order to validate the finite element model, the numerical results were compared to those obtained by experimental testing [21]. Particular attention will be given to the impact energy, contact load and delamination area in the composite laminate. In the initial stage, the contact force increases linearly due to elastic deformation of the carbon fiber and resin matrix. Intense oscillations occurring near the peak force value indicate initiation of damage. After the peak load, the crack of resin matrix gradually occurs and fiber tows appears to be damaged. All this induce the load decreasing gradually. During the impact event the impactor's kinetic energy is transferred to the composite plate once contact is made, until it reaches in equilibrium. Part of this energy is stored as elastic strain-energy and part is absorbed. The absorbed component results from the sum of the contributions given by non-conservative forces and the energy dissipated due to the failure mechanisms. Finally, the stored elastic energy is transferred to the impactor. The absorbed energy increases slowly in the early stage. Along with the increase of the displacement, resin crack and fiber breakage lead. The Fig. 6, present the displacement histories as function of the impact time for the three velocities. The displacements values were reported at the surface contact laminate-impactor. From the Fig. 6a (unnotched laminate), we note that the maximum displacement reached was of about $3.60 \mathrm{~mm}$ during time of about $1.61 \mathrm{~ms}$ obtained at the impact velocity of $4.17 \mathrm{~m} / \mathrm{s}$, the minimal displacement value was $2.18 \mathrm{~mm}$ at the time of $1.51 \mathrm{~ms}$ given by a velocity of $2.85 \mathrm{~m} / \mathrm{s}$, while at the velocity of $3.47 \mathrm{~m} / \mathrm{s}$, we obtain a displacement value of $2.86 \mathrm{~mm}$ for the impact time of $1.55 \mathrm{~ms}$. From Fig. $6 \mathrm{~b}$ circular notched laminate, the displacement increase by increasing the impact velocity. For the velocity of $4.17 \mathrm{~m} / \mathrm{s}$, the maximal displacement value was $3.87 \mathrm{~mm}$ (for $1.710 \mathrm{~ms}$ ), the lowest displacement value obtained for a velocity of $2.85 \mathrm{~m} / \mathrm{s}(2.23 \mathrm{~mm}$ during $1.48 \mathrm{~ms}$ ), while the velocity of $3.47 \mathrm{~m} / \mathrm{s}$ provide a value of $2.95 \mathrm{~mm}$ (for $1.52 \mathrm{~ms}$ ). We note that the circular notch increase the displacement values for the three velocities.

\subsection{Contact load and impact energy}

The contact load and the energy histories were reported in Fig. 7. The curves of impact energy have the same pace. The impact energy increase reaching a maximum value followed 


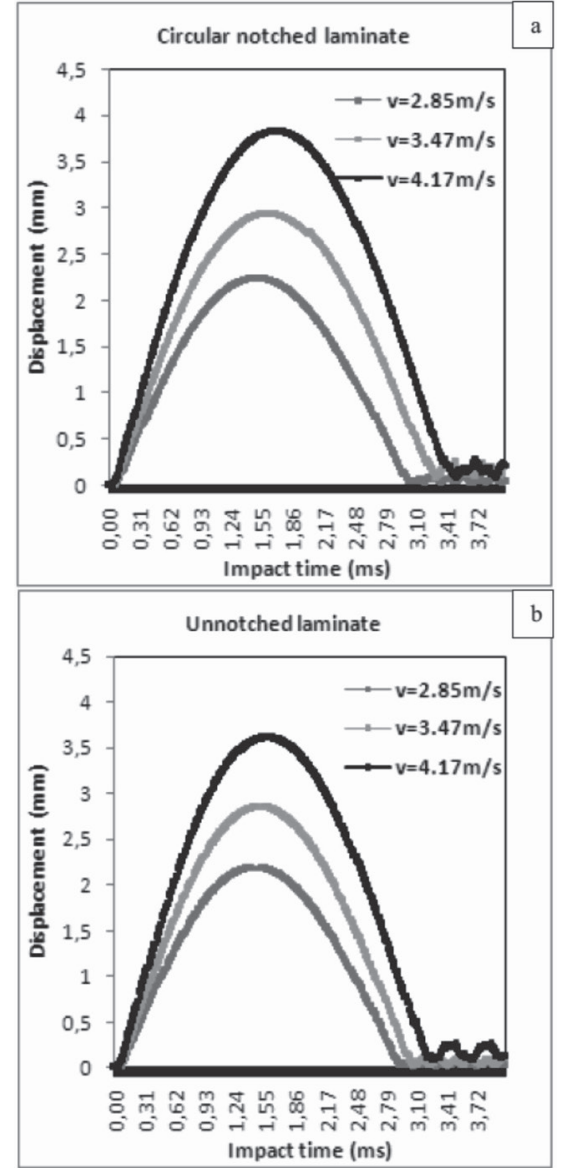

Fig. 6 Displacement histories as function of impact time

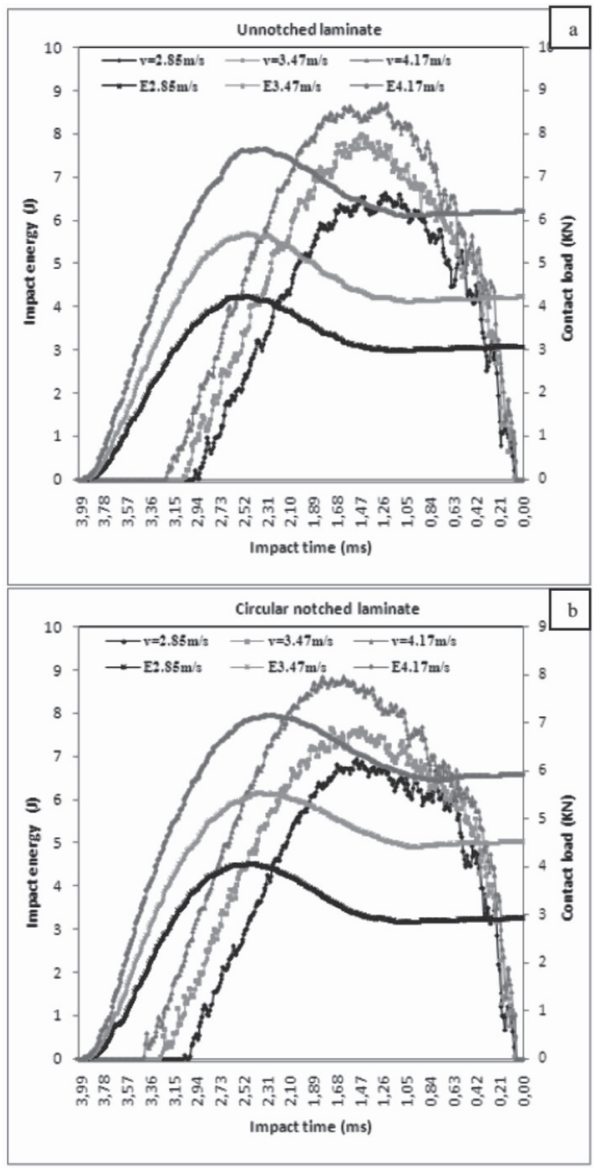

Fig. 7 Contact load and impact energy versus impact time history by a light decrease, and linear stabilization along the impact time. The maximum values of energy were obtained for impact velocity of $4.17 \mathrm{~m} / \mathrm{s}$, while velocity of $2.85 \mathrm{~m} / \mathrm{s}$ give a minimal values. From Fig. 7a, the velocity of $4.17 \mathrm{~m} / \mathrm{s}$ gives a maximum value of energy about $7.55 \mathrm{~J}$ during impact time of $1.55 \mathrm{~ms}$. The minimal impact energy was about of $4.18 \mathrm{~J}$ during $1.43 \mathrm{~s}$, while the intermediate value provided by impact velocity of $3.47 \mathrm{~m} / \mathrm{s}$ was $5.60 \mathrm{~J}$ during $1.45 \mathrm{~ms}$. In Fig. 7b, the impact energy increase in the case of notched laminate. The maximal value was obtained for a velocity of $4.17 \mathrm{~m} / \mathrm{s}$ (7.91 J during $1.67 \mathrm{~ms}$ ), while the velocity of $2.85 \mathrm{~m} / \mathrm{s}$ provide energy values of about $4.46 \mathrm{~J}(1.43 \mathrm{~ms})$. In Fig. 7, the impact load histories were reported as function of the impact time for a notched and unnotched laminate and velocities. The impact load increase until reaching a maximum value and decrease quickly. From Fig. 7a, in the case of unnotched laminate, the maximum load was reached at the velocity of $4.17 \mathrm{~m} / \mathrm{s}$ (impact energy 2063J) about $8.38 \mathrm{KN}$ during a time of $1.47 \mathrm{~ms}$, the velocity $3.47 \mathrm{~m} / \mathrm{s}$ provided a contact load of about $7.79 \mathrm{KN}$ for $1.39 \mathrm{~ms}$, while the velocity of $2.85 \mathrm{~m} / \mathrm{s}$ give a load about $6.50 \mathrm{KN}$ for $1.2 \mathrm{~ms}$. From Fig. 7b, we remark that the circular notched laminate decrease the contact load. For a velocity of $4.17 \mathrm{~m} / \mathrm{s}$, the maximal load was $7.80 \mathrm{KN}$ (for $1.6 \mathrm{~ms}$ ), while the minimal contact load was $6.11 \mathrm{KN}$ (for impact time of $1.46 \mathrm{~ms}$ ) given by a velocity of $2.85 \mathrm{~m} / \mathrm{s}$.

\subsection{Delamination area}

Delamination damage was implemented in the simulation model through the use of a contact_automatic_surface_to_surface tiebreak between the layers surface-to-surface tiebreak algorithm based on the knowledge of the interlaminar properties of the material in terms of normal and shear strengths with law option 6 [22] was adopted between separate solid elements modeling solid plies. Using this approach, each ply is modeled as a solid layer of elements, but the nodes between plies initially in contact are tied together, inhibiting sliding motions, until a failure criterion is reached, corresponding to delamination onset. In particular, the nodal stress is monitored throughout the analysis and implemented in the interface strengthbased failure criterion, Eq. (11).

$$
\left(\frac{\left|\sigma_{n}\right|}{N F L S}\right)^{2}+\left(\frac{\left|\sigma_{s}\right|}{S F L S}\right)^{2} \geq 1
$$

The delamination was reported in each layer interface as function of impact velocities for notched and unnotched laminate. From Fig. 8a, for velocity $2.85 \mathrm{~m} / \mathrm{s}$, the maximal 
delamination area was about of $34.38 \mathrm{~mm}^{2}$ obtained at the interface $(0 / 45)$ (tenth interface). The minimal delamination area was $3.72 \mathrm{~mm}^{2}$ at the interface $(45 / 0)$. The velocity of $3.47 \mathrm{~m} / \mathrm{s}$ gives a delamination area about $15.29 \mathrm{~mm}^{2}$, while the minimal value was $3.70 \mathrm{~mm}^{2}$ for $(0 / 45)$. The velocity of $4.17 \mathrm{~m} / \mathrm{s}$ give a value of $34.57 \mathrm{~mm}^{2}$ at the layer interface $(45 /-45)$, while the minimal value of the delamination area was $3.74 \mathrm{~mm}^{2}$ for $(45 / 0)$. At the velocity of $2.85 \mathrm{~m} / \mathrm{s}$, the delamination area was $9.53 \mathrm{~mm}^{2}$ at the interface $(45 / 0)$, the velocity of $3.47 \mathrm{~m} / \mathrm{s}$ provide a value of $21.64 \mathrm{~mm}^{2}$ at the interface $(45 / 45)$, while the impact velocity of $4.17 \mathrm{~m} / \mathrm{s}$ give a value of $7.87 \mathrm{~mm}^{2}$ at the interface $(0 / 0)$.
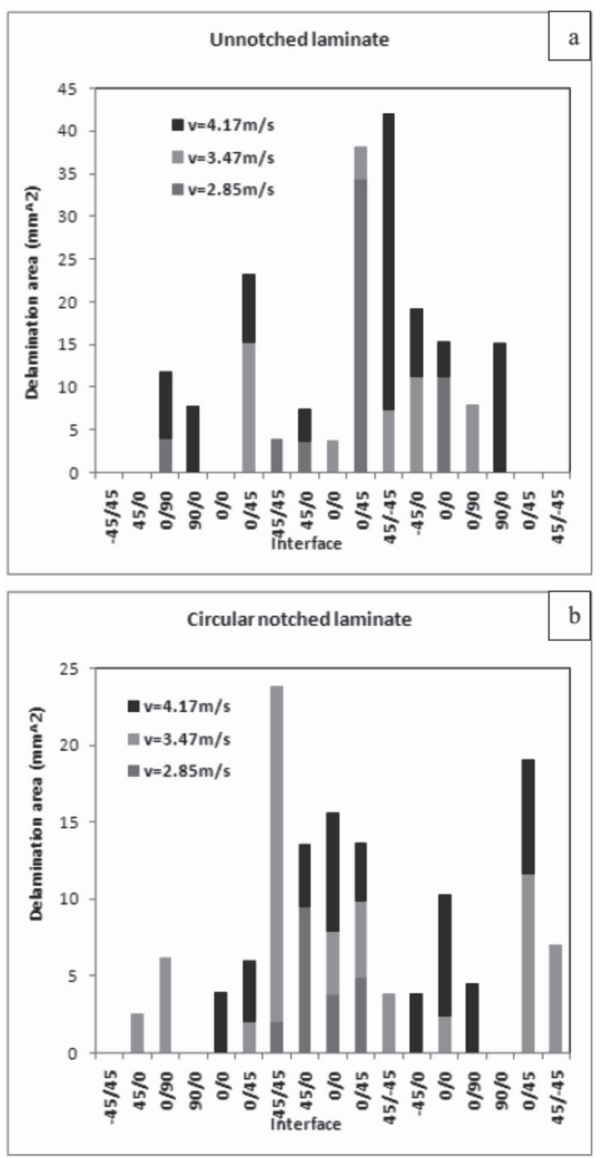

Fig. 8 Maximal delamination area at layer interfaces

\subsection{Comparison between FEM and experiment}

In order to validate the finite element model, a comparison had been made between the experimental and the numerical results. Figure 9A-B, show the comparison between the contact load and the displacement obtained from the numerical results and the drop test for unnotched and circular notched laminate. We can note that there is a good agreement between the Ls dyna finite element results and testing results. The numerical curves are so close to the experiment curve; Fiber fracture. In low energy or low velocity, the impactor rebounds from the specimen and causes less damage on it. By increasing the velocity, the contact force increase. But after exceeding the threshold value, contact force stops to increase. After the first fiber fractures, the amount of fibers that withstand the energy become less and less.

\subsection{Energy $\mathbf{G}_{\text {| }}$ and $\mathbf{G}_{\text {II }}$}

The energy release rate $\mathrm{G}_{\mathrm{I}}$ and $\mathrm{G}_{\mathrm{II}}$ were reported at each interface for unnotched and notched laminate for three impact velocities. From Fig. 10a, we note that the maximal value of $\mathrm{G}_{\mathrm{I}}$ $\left(0.00053 \mathrm{~J} / \mathrm{mm}^{2}\right.$ was obtained at interface $(0 / 45)$ provided by velocity of $3.47 \mathrm{~m} / \mathrm{s}$, while velocities of $2.85 \mathrm{~m} / \mathrm{s}$ and $4.17 \mathrm{~m} / \mathrm{s}$ gives more or less the same value of $\mathrm{G}_{\mathrm{I}}\left(0.00051 \mathrm{~J} / \mathrm{mm}^{2}\right)$ at the interface (45/-45). From Fig. 10b, the maximal value of $\mathrm{G}_{\mathrm{II}}$ $\left(0.000815 \mathrm{~J} / \mathrm{mm}^{2}\right)$ at the interface $(-45 / 0)$ provided by the impact velocity of $3.47 \mathrm{~m} / \mathrm{s}$, the minimal value $\left(0.000241 \mathrm{~J} / \mathrm{mm}^{2}\right)$ at the interface (45/-45) given by a velocity of $4.17 \mathrm{~m} / \mathrm{s}$. In Fig. $10 \mathrm{c}$, the maximal value of energy $\mathrm{G}_{\mathrm{I}}$ was $0.0019 \mathrm{~J} / \mathrm{mm}^{2}$ at the interface $(0 / 450$ provided by a velocity of $3.47 \mathrm{~m} / \mathrm{s}$, the minimal value was $0.00012 \mathrm{~J} / \mathrm{mm}^{2}$ at interface $(0 / 0)$ given by velocity of $4.17 \mathrm{~m} / \mathrm{s}$. At the same time, the values of the energy $G_{I I}$ (Fig. 10d) change in respect of the impact velocities. The velocity of $3.47 \mathrm{~m} / \mathrm{s}$ provides maximal value about of $0.00017 \mathrm{~J} / \mathrm{mm}^{2}$ at interface (-45/45). In Fig. 11, the delamination areas were represented at a velocity of $3.47 \mathrm{~m} / \mathrm{s}$. The size of delaminated surfaces is proportional to impact velocity. The delaminations are composed of the bottom interface layers. The circular notch had an effect on the growth of delamination area.

\section{Conclusion}

In this study, the impact behavior of circular notched and unnotched carbon/epoxy laminate composite plates at room ambient temperature is investigated. The objective of this experimental study was to determine the damages generated by the low and medium velocities with the help of experimental methods (Impact by a Drop Tower) and numerical modeling. The laminate was subjected to low and high velocity impact. The following conclusions can be drawn from the results obtained:

- The contact load and displacement increases by increasing the velocity impact.

- A good agreement between the numerical results and experimental results were observed.

- The circular notch had an effect on the impact behavior for different impact velocities.

A good agreement for contact loads and displacements were obtained between the finite element results and the experimental values obtained from a drop tower test. From the numerical results, we note that by increasing the velocity, the contact load, the displacement, the energy increase simultaneously. The circular notch had an effect on the behavior of the composite laminate. 
A)
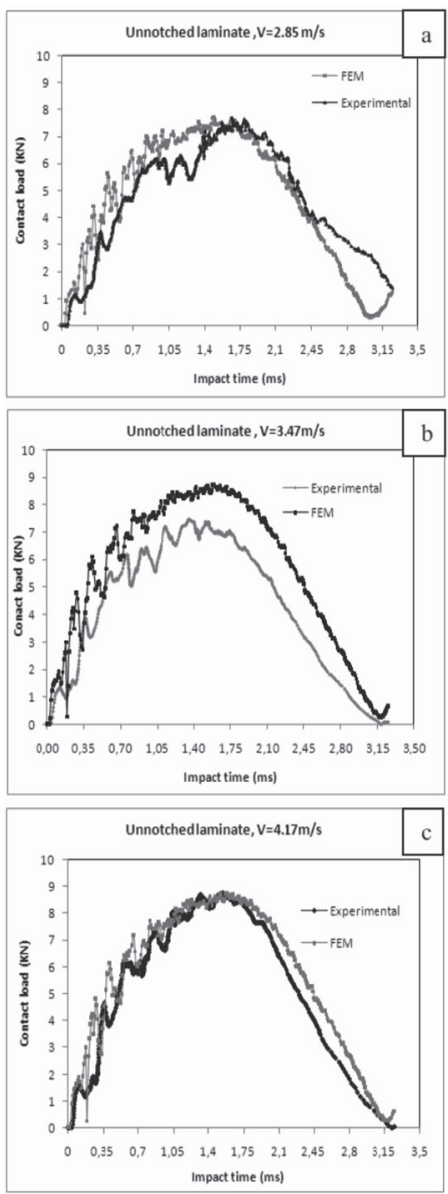

B)

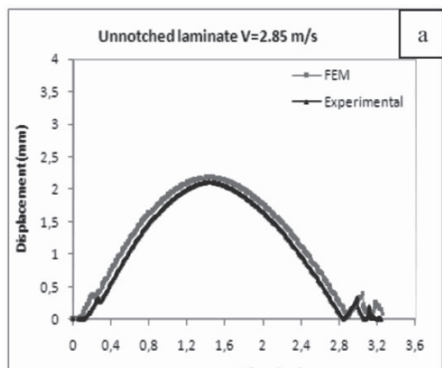

Impact time (ms)
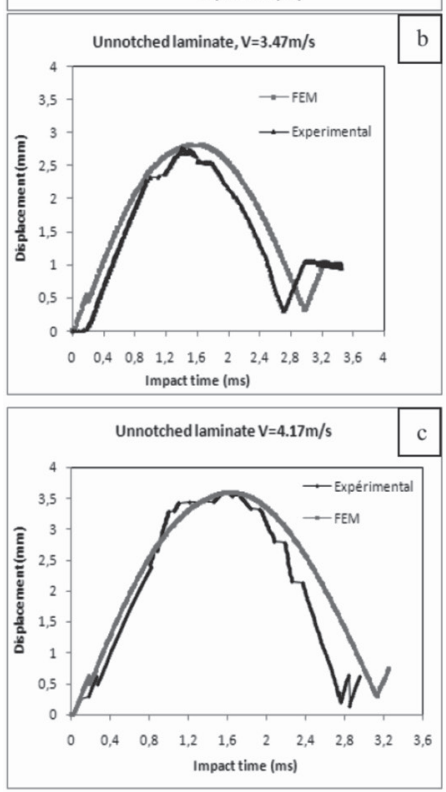

C)
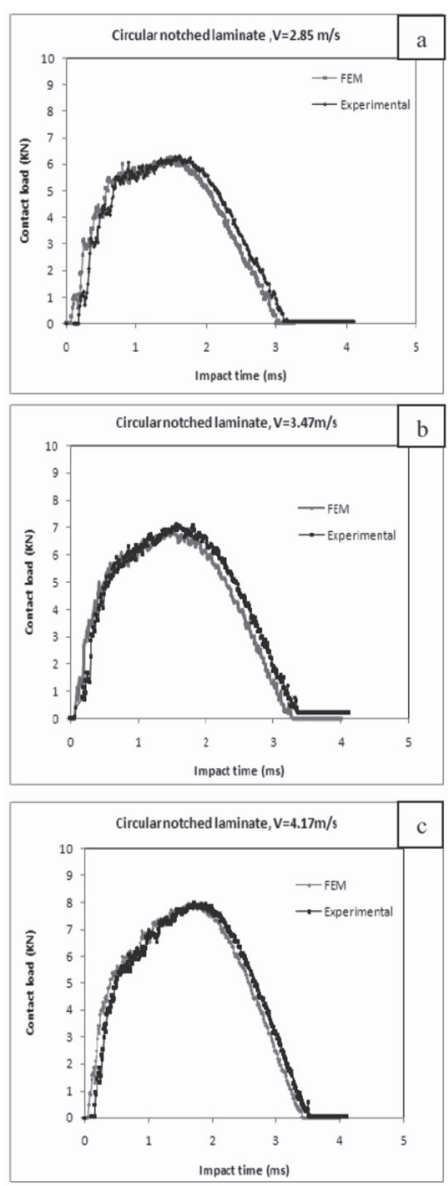

D)
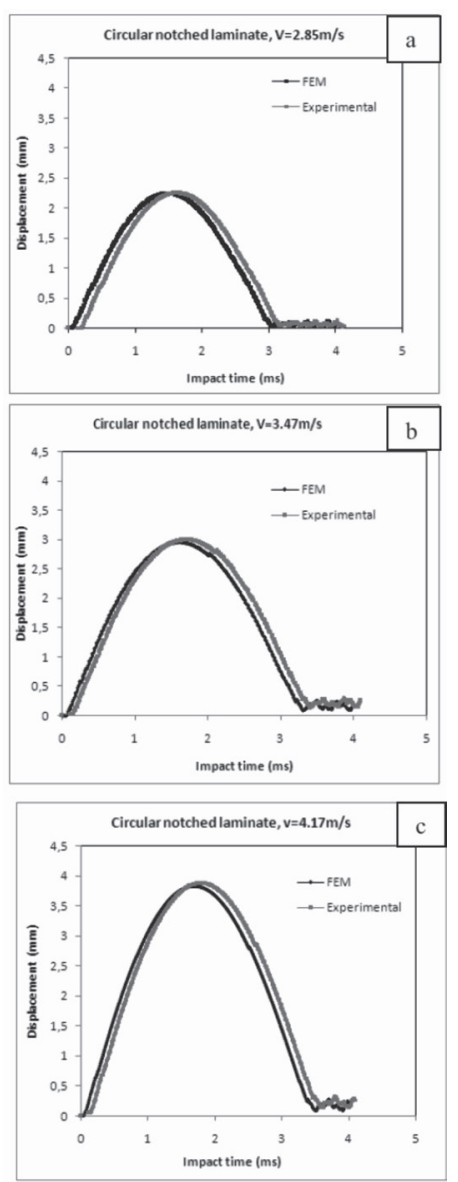

Fig. 9 A) Contact load for unnotched laminate; B) Displacement for unnotched laminate; C) Contact load for circular notched laminate; D) Displacement for notched laminate 

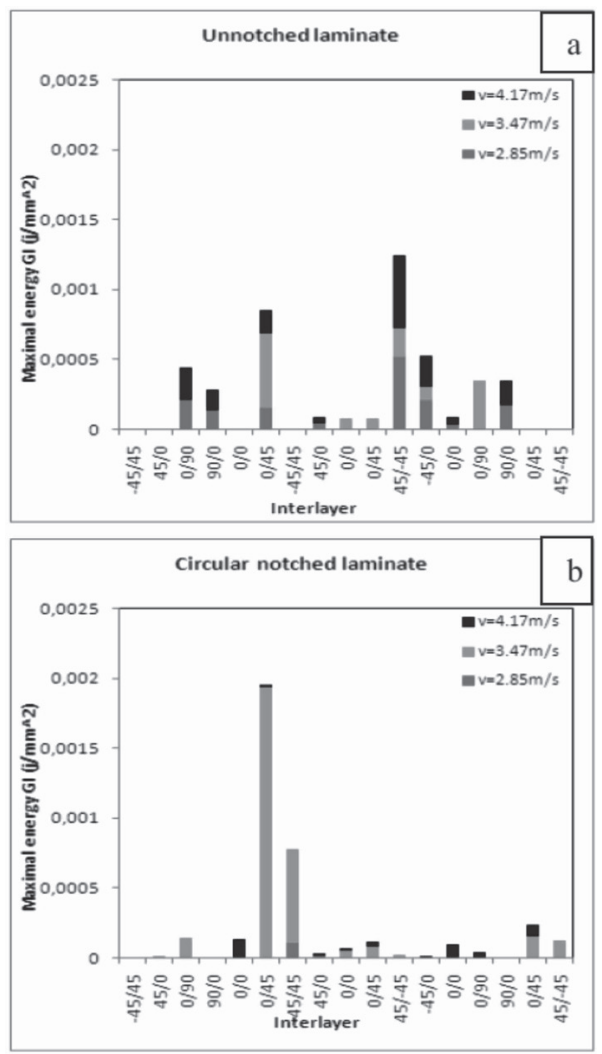
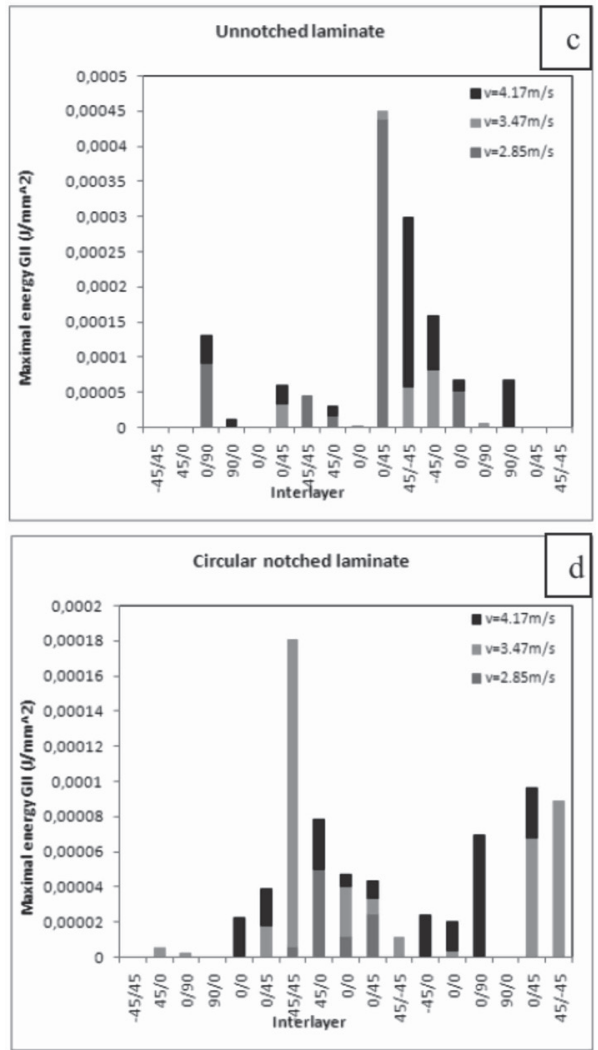

Fig. 10 Maximum $\mathrm{G}_{\mathrm{I}}$ and $\mathrm{G}_{\mathrm{II}}\left(\mathrm{J} / \mathrm{mm}^{2}\right)$ at interlayer
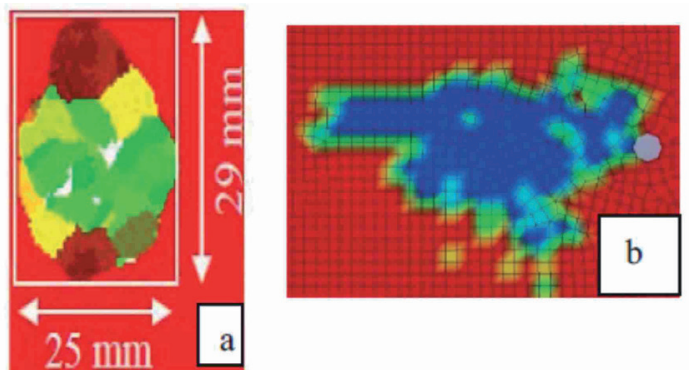

Fig. 11 Overall delamination area

\section{References}

[1] Abrate, S. "Modeling of impacts on composite structures." Composite Structures. 51(2), pp. 129-138. 2001.

DOI: 10.1016/s0263-8223(00)00138-0

[2] Iber, W. "Failure Mechanics in Low-Velocity Impacts on Thin Composite Plates." NASA Technical Paper 2152. 1983.

[3] Sjoblom, P. O., Harness, T. J. "On low Velocity Impact Testing of Composite Materials." Journal of Composite Materials. 22(1), pp. 30-52. 1988. DOI: $10.1177 / 002199838802200103$

[4] Waedle, B. L., Lagace, P. A. "On the Use of Dent Depth as an Impact Metric for Thin Composite Structures." Journal of Reinforced Plastics and Composites. 16(12), pp. 1093-1110. 1997.

DOI: $10.1177 / 073168449701601202$

[5] Kwon, Y. S, Sankar, B. V. "Indentation-Flexure and Low-Velocity Impact Damage in Graphite Epoxy Laminates." Journal of Composites Technology and Research. 15(2), pp. 101-111. 1993. DOI: 10.1520/CTR10361J

[6] Swanson, S. R. "Limits of Quasi-Static Solutions in Impact of Composite Structures." Composite Engineering. 2(4), pp. 261-267. 1992.

DOI: 10.1016/0961-9526(92)90009-u
[7] Husman, G. E., Whitney, J. M., Halpin, J. C. "Residual strength characterization of laminated composites subjected to impact loading." Foreign Object Impact Damage to Composites. 568, pp. 92-113. 1979. DOI: $10.1520 / \mathrm{stp} 33152 \mathrm{~s}$

[8] Roten, A. "Residual flexural strength of FRP composite specimens subjected to transverse impact loading." SAMPE Journal. 24(2), pp. 19-25. 1988.

[9] Abrate, S. "Impact on laminated composite materials." Applied Mechanics Reviews. 44(4), pp. 155-190. 1991. DOI: 10.1115/1.3119500

[10] de Freitas, M., Silva, A., Reis, L. "Numerical evaluation of failure mechanisms on composite specimens subjected to impact loading." Composites: Part B: Engineering. 31(3), pp. 199-207. 2000. DOI: $10.1016 / \mathrm{s} 1359-8368(00) 00003-2$

[11] Farooq, U., Gregory, K. "Finite Element Simulation of Low Velocity Impact Damage Morphology in Quasi Isotropic Composite Panels Under Variable Shape Impactors." European Journal of Scientific Research. 25(4), pp. 636-648. 2009.

[12] Tiberkak, R., Bachene, M., Rechak, S., Necib, B. "Damage prediction in composite plates subjected to low velocity impact." Composite Structures. 83(1), pp. 73-82. 2008. DOI: 10.1016/j.compstruct.2007.03.007

[13] Chen, J. K., Sun, C. T. "Dynamic large deflection response of composite laminates subjected to impact." Composite Structures. 4(1), pp. 5973.1985. DOI: 10.1016/0263-8223(85)90020-0

[14] Wu, H. Y. T., Chang, F. K. "Transient dynamic analysis of laminated composite plates subjected to transverse impact." Computers \& Structures. 31(3), pp. 453-466. 1989. DOI: 10.1016/0045-7949(89)90393-3

[15] Nilakantan, G., Keefe, M., Bogetti, T. A., Adkinson, R., Gillespie, J. W. "On the finite element analysis of woven fabric impact using multiscale modeling techniques." International Journal of Solid and Structures. 47(17), pp. 2300-2315. 2010. DOI: 10.1016/j.ijsolstr.2010.04.029 
[16] Khandelwal, M., Chakraborty, D., Dixit, U. S. "Delamination initiation in FRP laminated composites under low velocity impact." In: Proceedings of the International Conference on Mechanical Engineering 2003 (ICME2003), Dhaka, Banglades, Dec. 26-28, 2003.

[17] Mili, F., Necib, B. "The effect of stacking sequence on the impact-induced damage in cross-ply E-glass/epoxy composite plates." Archive of Applied Mechanics. 79(11), pp. 1019-1031. 2009.

DOI: $10.1007 / \mathrm{s} 00419-008-0272-\mathrm{Z}$

[18] Sun, B., Zhang, Y., Gu, B. "Low-Velocity Impact Response and Finite Element Analysis of Four-Step 3-D Braided Composites." Applied Composite Materials. 20(4), pp. 397-413. 2012.

DOI: $10.1007 / \mathrm{s} 10443-012-9279-2$

[19] Riccio, A., Di Felice, G., LaManna, G., Antonucci, E., Caputo, F., Lopresto, V., Zarrelli, M. "A Global-Local Numerical Model for the Prediction of Impact Induced Damage in Composite Laminates." Applied Composite Materials. 21(3), pp. 457-466. 2013.

DOI: $10.1007 / \mathrm{s} 10443-013-9343-6$
[20] ASTM D7136/D7136M-05 "Standard Test Method for Measuring the Damage Resistance of a Fiber-Reinforced Polymer Matrix Composite to a Drop-Weight Impact Event." ASTM International, West Conshohocken, PA, 2005. DOI: 10.1520/D7136_D7136M-05

[21] Ilyas, M. "Damage modeling of carbon epoxy laminated composites submitted to impact loading." Phd Thesis, University of Toulouse. 2010.

[22] LS-DYNA keyword user's manual. Version 971. Livermore: Livermore Software Technology Corporatio. 2007.

[23] Schweizerhof, K., Weimar, K., Münz, Th., Rottner, Th. "Crashworthiness analysis with enhanced composite material models in LS-DYNA merits and limits." In: LS- DYNA World Conference. Detroit, Michigan, USA, 1998 . 